\title{
Chinese College Students’ Typical English Pronunciation Errors
}

\author{
Wang Yifan ${ }^{a}$, Zhou Shiqian ${ }^{b, *}$, Chen Chuang ${ }^{c}$, Ban Yue ${ }^{d}$, Zhao Lu ${ }^{e}$ and Zhang Xiaoqing \\ School of Foreign Languages, Wuhan University of Technology, Luoshi Road, Wuhan, China \\ a570472827@qq.com, b464887584@qq.com, 'gavincen13@outlook.com, ${ }^{\mathrm{d} 917317746 @ q q . c o m, ~}{ }^{\mathrm{e}} 130371112$ \\ 39@qq.com, ${ }^{\mathrm{f}} 984490110 @ q q . c o m$ \\ *corresponding author
}

Keywords: dialects; language transfer; English pronunciation

\begin{abstract}
This paper studies the transfer impact of Chinese dialects on English pronunciation. Through the contrastive analysis of the recordings of all freshmen majoring in English from different dialect regions, and through related literature review, this paper analyzes the common and individual English pronunciation errors of every dialect region one by one, with the research results of this team in 2015 also taken into consideration. The results exhibit the ineffectiveness of English Pronunciation Course in correcting students' errors. Teachers should lead students to improve the pronunciation and avoid the negative transfer impact.
\end{abstract}

\section{Introduction}

Schachter proposes that language transfer is a restraint of the knowledge that language learners have previously learnt on the learning of the target language [1]. The research on language transfer has received special attention for a long time. Contrastive analysis had been popular in the 1950s. Lado's hypothesis of contrastive analysis thinks that language transfer is the major barrier of language acquisition; the similarity between two languages leads to positive transfer, while the difference leads to negative transfer; the distance between first language (L1) and target language is directly proportional to the difficulty of learning the target language [2]. In the 1970s, Nemser's "approximative system", Selinker's “interlanguage” and Kerashen's "input hypothesis" further elaborate on the impact of L1 on second language acquisition [3].

The research on the transfer impact of Chinese on English pronunciation has developed rapidly. In the 1940s, scholars including Zhao Yuanren and Lv Shuxiang etc. began to pay attention to the contrastive study of English and Chinese phonetics, and since then the research in this field has been advanced and formed a preliminary system in the early 21th century. In around 2010, it reached the peak [4]. A Comparison of the Main Features of Chinese and English Phonetic Systems by Professor Liu Naihua contrasts the two languages in phoneme, syllable, intonation, rhythm and juncture [5]. A Research on Changes in Sound Flow of English and Chinese by He Shanfen analyzes the two languages in terms of sound flow [6]. Language Transfer and Second Language Acquisition-Review, Reflection and Research by Yu Liming analyzes the impact of Chinese on English learning in terms of the complex influence of L1 on the target language [7]. However, both the comparison of pronunciations of English and Mandarin popular in the 20th century and the comparison of pronunciations of English and Chinese dialects in the 21th century focus mainly on the contrastive analysis of linguistic differences and similarities. The impact of Chinese on English learning and the effectiveness of English Pronunciation Course (the Course) in contemporary universities in improving students' English pronunciation are seldom studied.

This research will enhance people's understanding of Chinese college students' typical English pronunciation errors under the influence of Chinese dialects, and is conducive to analyzing the effectiveness of the Course in improving college students’ English pronunciation. 


\section{Research Design}

\subsection{Research Objects}

This research covers all the 103 freshmen majoring in English in The School of Foreign Languages, Wuhan University of Technology.

\subsection{Research Methods}

The research was conducted in two phases, through recording and questionnaires. The first recording was done when the objects first enter the University, and the second recording was done during their final test of the Course. After recording, analyzing and compiling statistics, the data of the two phases were compared for the quantitative effectiveness of the Course. This study was conducted only at the phonemic level.

\subsection{Research materials}

60 common words (Appendix) are adopted, covering all the phonemes needed that appear multiple times. The research done by the team in 2015 had used the same material. All are simple words, so every participant has no difficulty reading them, which ensures the effectiveness of the recordings.

\section{Recording Analysis}

From the statistics of the two-phase recording, this paper selects 11 consonants and 5 vowels, and analyzes the causes for their errors. Recordings are analyzed through the professional software Adobe Audition and errors are classified according to the dialect region and then compiled in Excel. They are calculated under the equation below:

Every error rate of every phoneme

$=$ (the times of this error of this phneme)/(the times of this phoneme $\times$ the number of recordings in this region - the number of invalid phonemes) $\times 100 \%$

Words mistaken for other words or omitted are invalid. After the statistics of all dialect regions are aggregated, only three errors with the highest rates of every phoneme are preserved. This paper does not include other dialect regions as most participants are from the Northern Dialect Region which is further divided into Southwest, Northwest, Jianghuai and Northern Sub-dialect Regions. The International Phonetic Alphabet (IPA) published by the International Phonetic Association in 2005 is far less popular than the English IPA in China. So for the convenience of recognition, this paper adopts English IPA and Chinese pinyin together. In the body the English IPA is expressed in "//", and pinyin on tables are in italics.

For convenience, this paper describes the error with the highest rate of every phoneme in every sub-dialect region as "the foremost error" (the FME), whose rate is called "the foremost error rate" (the FME rate).

\subsection{Consonants}

Statistics of the two-phase recording exhibit that the error rates of consonants $/ d /, / d z /$ and $/ \mathrm{z} /$ change considerably. Here are their analyses. 
Table 1 Statistics of Errors of /d/

\begin{tabular}{|c|c|c|c|c|c|c|c|c|c|c|c|c|c|c|c|c|}
\hline \multirow{3}{*}{ Correct } & \multicolumn{4}{|c|}{ SW } & \multicolumn{4}{|c|}{ NW } & \multicolumn{4}{|c|}{$\mathrm{JH}$} & \multicolumn{4}{|c|}{$\mathrm{N}$} \\
\hline & \multicolumn{2}{|c|}{ Phase 1} & \multicolumn{2}{|c|}{ Phase 2} & \multicolumn{2}{|c|}{ Phase 1} & \multicolumn{2}{|c|}{ Phase 2} & \multicolumn{2}{|c|}{ Phase 1} & \multicolumn{2}{|c|}{ Phase 2} & \multicolumn{2}{|c|}{ Phase 1} & \multicolumn{2}{|c|}{ Phase 2} \\
\hline & Error & Rate & Error & Rate & Error & Rate & Error & Rate & Error & Rate & Error & Rate & Error & Rate & Error & Rate \\
\hline \multirow{3}{*}{ d } & $\mathrm{t}$ & $47.15 \%$ & $\mathrm{t}$ & $49.38 \%$ & $\mathrm{t}$ & $41.27 \%$ & $\mathrm{t}$ & $43.55 \%$ & $\mathrm{t}$ & $38.89 \%$ & $\mathrm{t}$ & $50.00 \%$ & $\mathrm{t}$ & $30.08 \%$ & $\mathrm{t}$ & $38.66 \%$ \\
\hline & omitted & $1.49 \%$ & omitted & $2.22 \%$ & omitted & $1.59 \%$ & omitted & $3.23 \%$ & & & & & omitted & $1.69 \%$ & ts & $1.68 \%$ \\
\hline & də & $0.25 \%$ & ts & $0.25 \%$ & & & & & & & & & ts & $0.85 \%$ & omitted & $1.26 \%$ \\
\hline
\end{tabular}

Table 2 Statistics of Errors of /dz/

\begin{tabular}{|c|c|c|c|c|c|c|c|c|c|c|c|c|c|c|c|c|}
\hline \multirow{3}{*}{ Correct } & \multicolumn{4}{|c|}{ SW } & \multicolumn{4}{|c|}{ NW } & \multicolumn{4}{|c|}{$\mathrm{JH}$} & \multicolumn{4}{|c|}{$\mathrm{N}$} \\
\hline & \multicolumn{2}{|c|}{ Phase 1} & \multicolumn{2}{|c|}{ Phase 2} & \multicolumn{2}{|c|}{ Phase 1} & \multicolumn{2}{|c|}{ Phase 2} & \multicolumn{2}{|c|}{ Phase 1} & \multicolumn{2}{|c|}{ Phase 2} & \multicolumn{2}{|c|}{ Phase 1} & \multicolumn{2}{|c|}{ Phase 2} \\
\hline & Error & Rate & Error & Rate & Error & Rate & Error & Rate & Error & Rate & Error & Rate & Error & Rate & Error & Rate \\
\hline \multirow{3}{*}{$d_{3}$} & voiceless & $24.81 \%$ & voiceless & $28.36 \%$ & voiceless & $19.05 \%$ & voiceless & $28.57 \%$ & voiceless & $25.00 \%$ & voiceless & $25.00 \%$ & voiceless & $24.69 \%$ & voiceles & $26.58 \%$ \\
\hline & g & $6.02 \%$ & g & $5.22 \%$ & $z h$ & $14.29 \%$ & g & $9.52 \%$ & d3I & $8.33 \%$ & g & $16.67 \%$ & $z h$ & $14.81 \%$ & $z h$ & $12.66 \%$ \\
\hline & $\mathrm{t} \int$ & $5.26 \%$ & $\mathrm{t} \int$ & $2.99 \%$ & g & $9.52 \%$ & $z h$ & $9.52 \%$ & $\mathrm{~g}$ & $8.33 \%$ & & & $\mathrm{~g}$ & $4.94 \%$ & $\mathrm{~g}$ & $8.86 \%$ \\
\hline
\end{tabular}

Table 3 Statistics of Errors of /z/

\begin{tabular}{|c|c|c|c|c|c|c|c|c|c|c|c|c|c|c|c|c|}
\hline \multirow{3}{*}{ Correct } & \multicolumn{4}{|c|}{ SW } & \multicolumn{4}{|c|}{ NW } & \multicolumn{4}{|c|}{$\mathrm{JH}$} & \multicolumn{4}{|c|}{$\mathrm{N}$} \\
\hline & \multicolumn{2}{|c|}{ Phase 1} & \multicolumn{2}{|c|}{ Phase 2} & \multicolumn{2}{|c|}{ Phase 1} & \multicolumn{2}{|c|}{ Phase 2} & \multicolumn{2}{|c|}{ Phase 1} & \multicolumn{2}{|c|}{ Phase 2} & \multicolumn{2}{|c|}{ Phase 1} & \multicolumn{2}{|c|}{ Phase 2} \\
\hline & Error & Rate & Error & Rate & Error & Rate & Error & Rate & Error & \begin{tabular}{|l|} 
Rate \\
\end{tabular} & Error & Rate & Error & Rate & Error & Rate \\
\hline \multirow{3}{*}{$\mathrm{z}$} & $\mathrm{s}$ & $29.85 \%$ & $\mathrm{~s}$ & $34.33 \%$ & $\mathrm{~s}$ & $23.81 \%$ & $\mathrm{~s}$ & $21.05 \%$ & $\mathrm{~s}$ & $33.33 \%$ & 5 & $36.36 \%$ & $\mathrm{~s}$ & $30.77 \%$ & $\mathrm{~s}$ & $27.63 \%$ \\
\hline & & & $\mathrm{d}$ & $0.75 \%$ & & & ts & $5.26 \%$ & & & & & $\mathrm{~d}$ & $1.28 \%$ & & \\
\hline & & & ts & $0.75 \%$ & & & & & & & & & & & & \\
\hline
\end{tabular}

Table 1 shows that the rates of /t/, the FME of /d/ in all four sub-dialect regions, rise slightly from $47.5 \%, 41.27 \%, 38.89 \%$ and $30.08 \%$ in Phase 1 to $49.38 \%, 43.55 \%$, 50\% and $38.66 \%$ in Phase 2 respectively. The FME rates in two phases are both high. /t/ and /d/ have similar manners of articulation. The tip of the tongue is firmly against the middle of the alveolar ridge and when the tongue-tip is lowered suddenly from the teeth ridge the breath rushes out with a slight explosion or popping noise [8]. The difference is that /t/ is voiceless while /d/ is not [9]. The statistics also demonstrate that it is common for students to mix the two consonants. Table 2 shows that the FME of $/ \mathrm{d}_{3} /$ are all voiceless, and its rate in Jianghuai remains unchanged, while the rates in the other three sub-dialect regions increase slightly from 24.81\%, 19.05\% and 24.69\% in Phase 1 to 28.36\%, $28.57 \%$ and $26.58 \%$ in Phase 2. Table 3 shows that the FME of /z/ in all sub-dialect regions are /s/ whose rates remain over $20 \%$ in the two phases. There is $/ \mathrm{s} / \mathrm{but}$ no $/ \mathrm{z} /$ in Chinese phonetic system [10]. The initial consonant $\mathrm{z}$ - is an affricate different from the alveolar fricative /z/ [11], thus students find it harder to pronounce /z/ and tend to substitute /s/ for it. Most of the FME of /d/, /z/ and $/ \mathrm{d} z /$ in all sub-dialect regions are their corresponding voiceless consonants, which cannot be explained by the above theory. This error might be due to students' unfamiliarity with their phonetic symbols or distinctions between voiced and voiceless consonants, or they just want to save strength [4]. The Course has emphasized the coherence of pronouncing meaning groups, which is misunderstood by some students who thus pronounce the weak forms of $/ \mathrm{d} / \mathrm{and} / \mathrm{d} z /$ in meaning groups as voiceless consonants.

Table 4 Statistics of Errors of /ð/

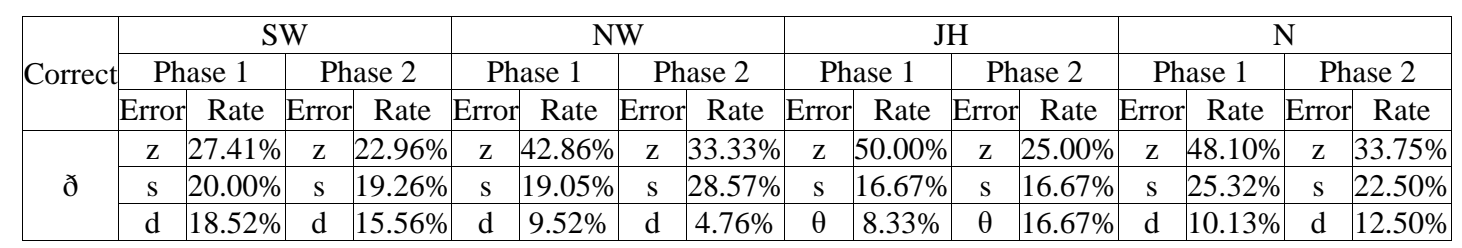

Table 5 Statistics of Errors of $/ \theta /$

\begin{tabular}{|c|c|c|c|c|c|c|c|c|c|c|c|c|c|c|c|c|}
\hline \multirow{3}{*}{ Correct } & \multicolumn{4}{|c|}{ SW } & \multicolumn{4}{|c|}{ NW } & \multicolumn{4}{|c|}{$\mathrm{JH}$} & \multicolumn{4}{|c|}{$\mathrm{N}$} \\
\hline & \multicolumn{2}{|c|}{ Phase 1} & \multicolumn{2}{|c|}{ Phase 2} & \multicolumn{2}{|c|}{ Phase 1} & \multicolumn{2}{|c|}{ Phase 2} & \multicolumn{2}{|c|}{ Phase 1} & \multicolumn{2}{|c|}{ Phase 2} & \multicolumn{2}{|c|}{ Phase 1} & \multicolumn{2}{|c|}{ Phase 2} \\
\hline & Error & Rate & Error & Rate & Error & Rate & Error & Rate & Error & Rate & Error & Rate & Error & Rate & Error & Rate \\
\hline \multirow{3}{*}{$\theta$} & s & $56.11 \%$ & s & $51.96 \%$ & s & $77.78 \%$ & s & $78.57 \%$ & $\mathrm{~s}$ & $75.00 \%$ & $\mathrm{~s}$ & $62.50 \%$ & $\mathrm{~s}$ & $75.24 \%$ & $\mathrm{~s}$ & $70.09 \%$ \\
\hline & $\mathrm{d}$ & $3.89 \%$ & & & $\mathrm{~d}$ & $11.11 \%$ & & & & & omitted & $6.25 \%$ & $\mathrm{~d}$ & $3.81 \%$ & $\int$ & $2.80 \%$ \\
\hline & omitted & $2.78 \%$ & & & & & & & & & & & $\mathrm{x}$ & $0.95 \%$ & & \\
\hline
\end{tabular}


Table 4 shows that the FME of /ð/ are all /z/ whose rates in the four sub-dialect regions decrease a little from $27.41 \%, 42.86 \%, 50 \%$ and $48.10 \%$ in Phase 1 to $22.96 \%$, 33.33\%, 25\% and 33.75\% in Phase 2. Table 5 shows that the FME of $/ \theta$ / in all sub-dialect regions are $/ \mathrm{s} /$ whose rates in the two phases are above 50\%. $/ \theta /$ has the error $/ \mathrm{d} /$ in the Southwest, Northwest and Northern Dialect Regions in Phase 1, but no in Phase 2, which demonstrates that students have correct understanding of this phoneme. But after the Course finishes, the FME rates of $/ \theta /$ and $/ ð /$ are still high. The reason should be that most Chinese dialects do not have $/ \theta /$ or $/ \delta /$, thus Chinese students substitute $/ \mathrm{s} /$ and /z/ that sound most similar for them [4]. Most students have known their right manners of articulation, but their difficulty and strength-demandingness will affect the fluency if students adopt the right manners without proficiency.

Table 6 Statistics of Errors of /l/

\begin{tabular}{|c|c|c|c|c|c|c|c|c|c|c|c|c|c|c|c|c|}
\hline \multirow{3}{*}{ Correct } & \multicolumn{4}{|c|}{ SW } & \multicolumn{4}{|c|}{ NW } & \multicolumn{4}{|c|}{$\mathrm{JH}$} & \multicolumn{4}{|c|}{$\mathrm{N}$} \\
\hline & \multicolumn{2}{|c|}{ Phase 1} & \multicolumn{2}{|c|}{ Phase 2} & \multicolumn{2}{|c|}{ Phase 1} & \multicolumn{2}{|c|}{$\begin{array}{l}\text { Phase } 2 \\
\end{array}$} & \multicolumn{2}{|c|}{ Phase 1} & \multicolumn{2}{|c|}{ Phase 2} & \multicolumn{2}{|c|}{ Phase 1} & \multicolumn{2}{|c|}{ Phase 2} \\
\hline & Error & Rate & Error & Rate & Error & Rate & Error & Rate & Error & Rate & Error & Rate & Error & Rate & Error & Rate \\
\hline \multirow{3}{*}{ l } & $0:$ & $18.21 \%$ & $0:$ & $15.58 \%$ & omitted. & $22.34 \%$ & omitted & $25.26 \%$ & o: & $13.21 \%$ & omitted & $18.18 \%$ & omitted & $22.59 \%$ & omitted & $22.40 \%$ \\
\hline & omitted & $11.98 \%$ & omitted & $15.58 \%$ & o: & $14.89 \%$ & o: & $14.74 \%$ & $\partial$ & $13.21 \%$ & $r$ & $10.91 \%$ & $0:$ & $20.66 \%$ & $5:$ & $17.49 \%$ \\
\hline & $\mathrm{r}$ & $10.86 \%$ & $\partial$ & $11.13 \%$ & $r$ & $7.45 \%$ & $\mathrm{r}$ & $10.53 \%$ & omitted & $11.32 \%$ & 0: & 9.09\% & $\partial U$ & $5.79 \%$ & D & $7.38 \%$ \\
\hline
\end{tabular}

Overall, the FME rates of /l/ do not change much. They decrease a little from $18.21 \%$ and $22.59 \%$ to $15.88 \%$ and $22.40 \%$ in Southwest and Northern Sub-dialect Regions, while they rise slightly from $22.34 \%$ and $13.21 \%$ to $25.26 \%$ and $18.18 \%$ in Northwest and Jianghuai Sub-dialect Regions respectively, which manifests the ineffectiveness of teaching this phoneme. Its FME remain unchanged in the two phases in Southwest, Northwest and Northern Sub-dialect Regions respectively, while only in Jianghuai it changes from $/ \mathrm{s} / /$ to "omitted", which means that students in this region tend to omit /l/ instead of substituting vowels for it after the Course. Dark /l/ neither appears at the end of syllables or before consonants in Chinese, nor does it constitute a syllable with a consonant before it [12]. "Students tend to use the Chinese -uo in place of /l/ in a syllable" [13]. The similarity between the English /o:/ and the Chinese -uo also explains why students from Southwest Sub-dialect Region pronounce /l/ as / $: /$.

Table 7 Statistics of Errors of $/ \mathrm{n} /$

\begin{tabular}{|c|c|c|c|c|c|c|c|c|c|c|c|c|c|c|c|c|}
\hline \multirow{3}{*}{ Correct } & \multicolumn{4}{|c|}{ SW } & \multicolumn{4}{|c|}{ NW } & \multicolumn{4}{|c|}{$\mathrm{JH}$} & \multicolumn{4}{|c|}{$\mathrm{N}$} \\
\hline & \multicolumn{2}{|c|}{ Phase 1} & \multicolumn{2}{|c|}{ Phase 2} & \multicolumn{2}{|c|}{ Phase 1} & \multicolumn{2}{|c|}{ Phase 2} & \multicolumn{2}{|c|}{ Phase 1} & \multicolumn{2}{|c|}{ Phase 2} & \multicolumn{2}{|c|}{ Phase 1} & \multicolumn{2}{|c|}{ Phase 2} \\
\hline & Error & Rate & Error & Rate & Error & Rate & Error & Rate & Error & Rate & Error & Rate & Error & Rate & Error & Rate \\
\hline \multirow{3}{*}{$\mathrm{n}$} & y & $10.86 \%$ & $\eta$ & $11.32 \%$ & $y$ & $15.00 \%$ & y & $15.00 \%$ & $\eta$ & $17.39 \%$ & $\eta$ & $17.39 \%$ & $\mathrm{y}$ & $5.16 \%$ & $y$ & $3.21 \%$ \\
\hline & l & $4.87 \%$ & l & $4.15 \%$ & omitted & $5.00 \%$ & & & omitted & $4.35 \%$ & & & omitted & $3.87 \%$ & omitted & $1.92 \%$ \\
\hline & omitted & $2.62 \%$ & omitted & $1.89 \%$ & & & & & & & & & & & $\mathrm{l}$ & $0.64 \%$ \\
\hline
\end{tabular}

Table 8 Statistics of Errors of $/ \mathrm{y} /$

\begin{tabular}{|c|c|c|c|c|c|c|c|c|c|c|c|c|c|c|c|c|}
\hline \multirow{3}{*}{ Correct } & \multicolumn{4}{|c|}{ SW } & \multicolumn{4}{|c|}{ NW } & \multicolumn{4}{|c|}{$\mathrm{JH}$} & \multicolumn{4}{|c|}{$\mathrm{N}$} \\
\hline & \multicolumn{2}{|c|}{ Phase 1} & \multicolumn{2}{|c|}{ Phase 2} & \multicolumn{2}{|c|}{ Phase 1} & \multicolumn{2}{|c|}{ Phase 2} & \multicolumn{2}{|c|}{ Phase 1} & \multicolumn{2}{|c|}{ Phase 2} & \multicolumn{2}{|c|}{ Phase 1} & \multicolumn{2}{|c|}{ Phase 2} \\
\hline & Error & Rate & Error & Rate & Error & Rate & Error & Rate & Error & Rate & Error & Rate & Error & Rate & Error & Rate \\
\hline & $\mathrm{n}$ & $54.44 \%$ & $\mathrm{n}$ & $53.07 \%$ & $\mathrm{n}$ & $60.71 \%$ & $\mathrm{n}$ & $57.14 \%$ & $\mathrm{n}$ & $50.00 \%$ & $\mathrm{n}$ & $50.00 \%$ & $\mathrm{n}$ & $60.75 \%$ & $\mathrm{n}$ & $54.21 \%$ \\
\hline & omitted & $8.33 \%$ & omitted & $1.12 \%$ & omitted & $7.14 \%$ & & & omitted & $25.00 \%$ & & & omitted & $14.02 \%$ & omitted & $1.87 \%$ \\
\hline
\end{tabular}

Table 7 shows that the FME of $/ \mathrm{n} /$ in all sub-dialect regions are $/ \mathrm{y} /$ whose rates do not change much in the two phases, and Table 8 shows that the FME of $/ \mathrm{y} /$ in all sub-dialect regions are $/ \mathrm{n} /$ whose rates remain high in the two phases, which exhibits that it is common for students to mix the two consonants. Many Chinese dialects have only front nasal final $/ \mathrm{n} /$ or only back nasal final $/ \mathrm{y} /$. For example, the characters pronounced as -en and -in in Xiajiang dialect are pronounced as -eng and -ing in Southwest dialect [14]. This articulating habit has been transferred to English pronunciation, thus students from all sub-dialect regions are inclined to mix the two phonemes, which has not been corrected effectively in pronunciation teaching. 
Table 9 Statistics of Errors of /t $\mathrm{g} /$

\begin{tabular}{|c|c|c|c|c|c|c|c|c|c|c|c|c|}
\hline \multirow{3}{*}{ Correct } & \multicolumn{4}{|c|}{ SW } & \multicolumn{4}{c|}{ NW } & \multicolumn{4}{c|}{$\mathrm{N}$} \\
\cline { 2 - 12 } & Phase 1 & Phase 2 & \multicolumn{2}{c|}{ Phase 1 } & Phase 2 & \multicolumn{2}{c|}{ Phase 1 } & \multicolumn{2}{c|}{ Phase 2 } \\
\cline { 2 - 11 } & Error & Rate & Error & Rate & Error & Rate & Error & Rate & Error & Rate & Error & Rate \\
\hline \multirow{2}{*}{ t } & t & $1.49 \%$ & $\int$ & $1.50 \%$ & ch & $14.29 \%$ & ch & $20.00 \%$ & ch & $9.88 \%$ & ch & $8.97 \%$ \\
\cline { 2 - 12 } & & & t & $1.50 \%$ & & & & & ts & $3.70 \%$ & t & $1.28 \%$ \\
\hline
\end{tabular}

Table 9 shows that on the whole, the FME rates of /t $\mathrm{f} /$ keep stable, except that in the Northern Sub-dialect Region rises slightly from $14.29 \%$ to $20.00 \%$, which means that students from this region are under greater impact of the dialect when pronouncing it. People in some areas including Jilin in Northeast China tend to mix flat tongues "z-, s-, c-" and retroflex consonants "zh-, sh-, ch-”. People in Harbin often mistake "z-, s-, c-" for "zh-, sh-, ch-" [15]. Therefore, for students in Northern Dialect Region, /t $\mathrm{f} /$ sounds more like the Chinese ch- [4]. Students like using the Chinese ch- in place of the English $/ \mathrm{t} / /$ and they have not paid enough attention to it. During pronunciation teaching teachers have not pointed out clearly the difference between / $\mathrm{t} /$ and its FME ch-, hence the ineffective improvement.

Table 10 Statistics of Errors of /v/

\begin{tabular}{|c|c|c|c|c|c|c|c|c|c|c|c|c|c|c|c|c|}
\hline \multirow{3}{*}{ Correct } & \multicolumn{4}{|c|}{ SW } & \multicolumn{4}{|c|}{ NW } & \multicolumn{4}{|c|}{$\mathrm{JH}$} & \multicolumn{4}{|c|}{$\mathrm{N}$} \\
\hline & \multicolumn{2}{|c|}{ Phase 1} & \multicolumn{2}{|c|}{ Phase 2} & \multicolumn{2}{|c|}{ Phase 1} & \multicolumn{2}{|c|}{ Phase 2} & \multicolumn{2}{|c|}{ Phase 1} & \multicolumn{2}{|c|}{ Phase 2} & \multicolumn{2}{|c|}{ Phase 1} & \multicolumn{2}{|c|}{ Phase 2} \\
\hline & Error & Rate & Error & Rate & Error & Rate & Error & Rate & Error & Rate & Error & Rate & Error & Rate & Error & Rate \\
\hline $\mathrm{V}$ & $\mathrm{w}$ & $3.33 \%$ & W & $5.56 \%$ & $\mathrm{w}$ & $42.86 \%$ & $\mathrm{w}$ & $50.00 \%$ & W & $50.00 \%$ & & & W & $50.94 \%$ & $\mathrm{w}$ & $41.51 \%$ \\
\hline
\end{tabular}

Table 10 shows that the FME of /v/ in all sub-dialect regions are /w/. Its rate in Southwest keeps under 6\%, while in Jianghuai and Northern the rates decrease from 50\% and $50.94 \%$ to $0 \%$ and 41.51\%, and in Northwest it increases from $42.86 \%$ to $50.00 \%$. Its error rates in Northwest are high, and even increase after pronunciation course, save that students in Jianghuai have mastered this phoneme well after it. Most Chinese dialects do not have the voiced labiodental fricative v- except that Linyi dialect has it which is disappearing gradually in the evolving dialectal system [16]. Therefore, students find it hard to pronounce /v/ and tend to mistake it for the voiced bilabial-velar glide /w/ [17]. Although teachers have emphasized the distinction between /v/ and /w/, it is still hard for students to pronounce correctly under the influence of articulating habits.

Table 11 Statistics of Errors of /3/

\begin{tabular}{|c|c|c|c|c|c|c|c|c|c|c|c|c|c|c|c|c|}
\hline \multirow{3}{*}{ Correct } & \multicolumn{4}{|c|}{ SW } & \multicolumn{4}{|c|}{ NW } & \multicolumn{4}{|c|}{$\mathrm{JH}$} & \multicolumn{4}{|c|}{$\mathrm{N}$} \\
\hline & \multicolumn{2}{|c|}{ Phase 1} & \multicolumn{2}{|c|}{ Phase 2} & \multicolumn{2}{|c|}{ Phase 1} & \multicolumn{2}{|c|}{ Phase 2} & \multicolumn{2}{|c|}{ Phase 1} & \multicolumn{2}{|c|}{ Phase 2} & \multicolumn{2}{|c|}{ Phase 1} & \multicolumn{2}{|c|}{ Phase 2} \\
\hline & Error & Rate & Error & Rate & Error & Rate & Error & Rate & Error & Rate & Error & Rate & Error & Rate & Error & Rate \\
\hline & $\mathrm{d}_{3}$ & $40.15 \%$ & $\mathrm{~d}_{3}$ & $41.79 \%$ & $\mathrm{r}$ & $75.00 \%$ & $\mathrm{r}$ & $42.11 \%$ & $\mathrm{~d}_{3}$ & $36.36 \%$ & $\int$ & $41.67 \%$ & $\mathrm{r}$ & $52.00 \%$ & $\mathrm{r}$ & $47.95 \%$ \\
\hline & $\mathrm{j}$ & $26.52 \%$ & $j$ & $19.40 \%$ & $d_{3}$ & $10.00 \%$ & $d_{3}$ & $15.79 \%$ & $\mathrm{j}$ & $27.27 \%$ & $d_{3}$ & $16.67 \%$ & $d_{3}$ & $14.67 \%$ & $d_{3}$ & $13.70^{\circ}$ \\
\hline & $\int$ & $15.91 \%$ & $\int$ & $17.91 \%$ & $\mathrm{~s}$ & $5.00 \%$ & $\int$ & $15.79 \%$ & $\int$ & $18.18 \%$ & $\mathrm{j}$ & $16.67 \%$ & $\int$ & $8.00 \%$ & zh & $12.33 \%$ \\
\hline
\end{tabular}

The rate of $/ \mathrm{r}$, the FME of / 3 / in Northwest Dialect Region, decreases form $75.00 \%$ to $42.11 \%$, which exhibits high effectiveness of teaching. In Jianghuai Dialect Region, the rate of error /dz/ of $/ 3 /$ declines from $36.36 \%$ to $16.7 \%$, and the rate of error $/ \mathrm{f} /$ grows from $18.18 \%$ to $41.67 \%$. Statistics show that in Northwest and Northern Dialect Regions $/ r /$ is the FME of $/ 3 /$. $/ 3 /$ does not exist at all in Chinese, posing grave difficulty for Chinese students who tend to use the Chinese rinstead [17]. Its FME changes from /dz/ to / $/$ in Jianghuai. / $/ /$ and $/ 3 /$ have the same articulating position, but $/ \mathrm{J} /$ is voiceless and requires stronger breath-pushing, while $/ 3 /$ is voiced and requires weaker breath-pushing [8]. The similarity makes it harder for students to distinguish between the two consonants. For students from different dialect regions, teachers should teach differently in the Course. For example, students from Jianghuai Sub-dialect Region should be paid extra attention to in terms of pronouncing $/ 3 /$. 


\subsection{Vowels}

Table 12 Statistics of Errors of /e/

\begin{tabular}{|c|c|c|c|c|c|c|c|c|c|c|c|c|c|c|c|c|}
\hline \multirow{3}{*}{ Correct } & \multicolumn{4}{|c|}{ SW } & \multicolumn{4}{|c|}{ NW } & \multicolumn{4}{|c|}{$\mathrm{JH}$} & \multicolumn{4}{|c|}{$\mathrm{N}$} \\
\hline & \multicolumn{2}{|c|}{ Phase 1} & \multicolumn{2}{|c|}{ Phase 2} & \multicolumn{2}{|c|}{ Phase 1} & \multicolumn{2}{|c|}{ Phase 2} & \multicolumn{2}{|c|}{ Phase 1} & \multicolumn{2}{|c|}{ Phase 2} & \multicolumn{2}{|c|}{ Phase 1} & \multicolumn{2}{|c|}{ Phase 2} \\
\hline & Error & Rate & Error & Rate & Error & Rate & Error & Rate & Error & Rate & Error & Rate & Error & Rate & Error & Rate \\
\hline & I & $6.05 \%$ & I & $6.71 \%$ & I & $14.58 \%$ & I & $17.02 \%$ & I & $7.14 \%$ & I & $14.29 \%$ & aI & $3.76 \%$ & I & $6.99 \%$ \\
\hline & $\Lambda$ & $1.59 \%$ & aI & $1.92 \%$ & aI & $2.08 \%$ & aI & $4.26 \%$ & $\mathrm{i}:$ & $3.57 \%$ & & & I & $3.76 \%$ & aI & $2.69 \%$ \\
\hline & eI & $1.27 \%$ & æ & $0.96 \%$ & i: & $2.08 \%$ & $\mathrm{p}$ & $2.13 \%$ & & & & & $\mathrm{i}:$ & $3.23 \%$ & or & $1.61 \%$ \\
\hline
\end{tabular}

In Table 12, except that the FME of /e/ in Northern Sub-dialect Region in Phase 1 is /ai/, that in every other sub-dialect region in each phase is $/ \mathrm{I} /$, and that in Northern Sub-dialect Region in Phase 2 is also /I/. The FME rates of /e/ in the three sub-dialect regions except Northern Dialect-Region increase from $6.05 \%, 14.58 \%$ and $7.14 \%$ to $6.71 \%, 17.02 \%$ and $14.29 \%$, while it in Northern Sub-dialect Region rises from 3.76\% (/ar/) to 6.99\% (/I/). Although the numbers are not high, this slight increase still indicates that students has not well learnt this phoneme and tended to confuse it with the similar /I/. /I/ is a mid-close front-central vowel while /e/ is a mid front vowel [18]. They have similar articulating positions, which are thus hard for students to distinguish.

Table 13 Statistics of Errors of /I/

\begin{tabular}{|c|c|c|c|c|c|c|c|c|c|c|c|c|c|c|c|c|}
\hline \multirow{3}{*}{ Correct } & \multicolumn{4}{|c|}{ SW } & \multicolumn{4}{|c|}{ NW } & \multicolumn{4}{|c|}{$\mathrm{JH}$} & \multicolumn{4}{|c|}{$\mathrm{N}$} \\
\hline & \multicolumn{2}{|c|}{ Phase 1} & \multicolumn{2}{|c|}{ Phase 2} & \multicolumn{2}{|c|}{ Phase 1} & \multicolumn{2}{|c|}{ Phase 2} & \multicolumn{2}{|c|}{ Phase 1} & \multicolumn{2}{|c|}{ Phase 2} & \multicolumn{2}{|c|}{ Phase 1} & \multicolumn{2}{|c|}{ Phase 2} \\
\hline & Error & Rate & Error & Rate & Error & Rate & Error & Rate & Error & Rate & Error & Rate & Error & Rate & Error & Rate \\
\hline & i: & $13.75 \%$ & i: & $2.61 \%$ & i: & $10.84 \%$ & i: & $8.64 \%$ & i: & $8.33 \%$ & i: & $8.51 \%$ & i: & $16.25 \%$ & $\mathrm{i}:$ & $5.40 \%$ \\
\hline & e & $0.93 \%$ & In & $0.37 \%$ & e & $1.20 \%$ & In & $1.23 \%$ & & & & & e & $1.56 \%$ & e & $0.63 \%$ \\
\hline & In & $0.19 \%$ & e & $0.19 \%$ & In & $1.20 \%$ & & & & & & & aI & $0.31 \%$ & In & $0.63 \%$ \\
\hline
\end{tabular}

Table 14 Statistics of Errors of / i:/

\begin{tabular}{|c|c|c|c|c|c|c|c|c|c|c|c|c|c|c|c|c|}
\hline \multirow{3}{*}{ Correct } & \multicolumn{4}{|c|}{ SW } & \multicolumn{4}{|c|}{ NW } & \multicolumn{4}{|c|}{$\mathrm{JH}$} & \multicolumn{4}{|c|}{$\mathrm{N}$} \\
\hline & \multicolumn{2}{|c|}{ Phase 1} & \multicolumn{2}{|c|}{ Phase 2} & \multicolumn{2}{|c|}{ Phase 1} & \multicolumn{2}{|c|}{ Phase 2} & \multicolumn{2}{|c|}{ Phase 1} & \multicolumn{2}{|c|}{ Phase 2} & \multicolumn{2}{|c|}{ Phase 1} & \multicolumn{2}{|c|}{ Phase 2} \\
\hline & Error & Rate & Error & Rate & Error & Rate & Error & Rate & Error & Rate & Error & Rate & Error & Rate & Error & Rate \\
\hline \multirow{3}{*}{ i: } & I & $4.46 \%$ & I & $10.22 \%$ & I & $6.12 \%$ & I & $12.50 \%$ & e & $3.57 \%$ & I & $3.70 \%$ & e & $3.78 \%$ & I & $6.95 \%$ \\
\hline & $\mathrm{e}$ & $2.87 \%$ & $\mathrm{e}$ & $4.47 \%$ & $\mathrm{e}$ & $4.08 \%$ & $\mathrm{e}$ & $6.25 \%$ & I & $3.57 \%$ & & & I & $1.62 \%$ & $\mathrm{e}$ & $2.67 \%$ \\
\hline & аI & $0.32 \%$ & ər & $0.32 \%$ & i:n & $2.04 \%$ & aI & $2.08 \%$ & & & & & aI & $0.54 \%$ & i:n & $0.53 \%$ \\
\hline
\end{tabular}

In Table 13, the FME of /I/ in all the four sub-dialect regions are /i:/ whose rates in Southwest, Northwest, and Northern Sub-dialect Regions decrease from 13.75\%, 10.84\% and 16.25\% to 2.61\%, 8.64\% and 5.40\% respectively, and it in Jianghuai remained at around 8.3\%. In Table 14, the FME rates of /i:/ in Southwest, Northwest, Jianghuai and Northern Sub-dialect Regions increase from $4.46 \%, 6.12 \%, 3.57 \%$ and $3.78 \%$ to $10.22 \%, 12.50 \%, 3.70 \%$ and $6.95 \%$ respectively. English has obvious long and short sounds, while the lengths of Chinese sounds do not vary much [19]. Therefore, under the influence of Chinese articulating habits, students often shorten long vowels, and prolong short vowels, which results in the confusion between /i:/ and /I/. Also, students tend to easily distinguish between /i:/ and /I/ in stressed syllables, but ignore their difference in unstressed syllables [20]. They have different tongue positions besides their lengths. In pronunciation teaching, teachers have repeatedly emphasized the distinctions between the two phonemes, but the similarity makes it difficult for Chinese students to tell them apart, which causes the error rates to be hard to decrease.

Table 15 Statistics of Errors of /u:/

\begin{tabular}{|c|c|c|c|c|c|c|c|c|c|c|c|c|c|c|c|c|}
\hline \multirow{3}{*}{ Correct } & \multicolumn{4}{|c|}{ SW } & \multicolumn{4}{|c|}{ NW } & \multicolumn{4}{|c|}{$\mathrm{JH}$} & \multicolumn{4}{|c|}{$\mathrm{N}$} \\
\hline & \multicolumn{2}{|c|}{ Phase 1} & \multicolumn{2}{|c|}{ Phase 2} & \multicolumn{2}{|c|}{ Phase 1} & \multicolumn{2}{|c|}{ Phase 2} & \multicolumn{2}{|c|}{ Phase 1} & \multicolumn{2}{|c|}{ Phase 2} & \multicolumn{2}{|c|}{ Phase 1} & \multicolumn{2}{|c|}{ Phase 2} \\
\hline & Error & Rate & Error & Rate & Error & Rate & Error & Rate & Error & Rate & Error & Rate & Error & Rate & Error & Rate \\
\hline \multirow{3}{*}{$\mathrm{u}:$} & $v$ & $15.56 \%$ & $v$ & $12.59 \%$ & o: & $9.52 \%$ & o: & $23.81 \%$ & v & $33.33 \%$ & o: & $8.33 \%$ & o: & $19.75 \%$ & o: & $14.81 \%$ \\
\hline & $0:$ & $5.19 \%$ & o: & $4.44 \%$ & $\partial U$ & $9.52 \%$ & U & $14.29 \%$ & $0:$ & $8.33 \%$ & v & $8.33 \%$ & U & $7.41 \%$ & v & $9.88 \%$ \\
\hline & & & $\partial U$ & $0.74 \%$ & v & $9.52 \%$ & $\partial \sigma$ & $4.76 \%$ & & & & & $\partial U$ & $1.23 \%$ & $\partial U$ & $1.23 \%$ \\
\hline
\end{tabular}

The error rates of /u:/ are generally low, but its FME rate in Jianghuai Sub-dialect Region drops 
from $33.33 \%$ to $8.33 \%$, which indicates that students from there pronounce it under marked influence of the dialect, but the Course has corrected it effectively. Its FME rates in Southwest and Northern Sub-dialect Regions reduce from $15.56 \%$ and $19.76 \%$ to $12.59 \%$ and $14.81 \%$, which indicates that the course has improved students' pronunciation of the phoneme. Its FME rate in Northwest Sub-dialect Region increases from $9.52 \%$ to $23.81 \%$ and students tend to substitute $/ 0: /$ with a similar articulating position for it. The long vowel /u:/ is similar to the Chinese $-\mathrm{u}$, but the short vowel /ð/ does not exist in Chinese [17]. They look similar, and thus are easily confused by students.

Table 16 Statistics of Errors of /ひə/

\begin{tabular}{|c|c|c|c|c|c|c|c|c|c|c|c|c|c|c|c|c|}
\hline \multirow{3}{*}{ Correct } & \multicolumn{4}{|c|}{ SW } & \multicolumn{4}{|c|}{ NW } & \multicolumn{4}{|c|}{$\mathrm{JH}$} & \multicolumn{4}{|c|}{$\mathrm{N}$} \\
\hline & \multicolumn{2}{|c|}{ Phase 1} & \multicolumn{2}{|c|}{\begin{tabular}{|l|} 
Phase 2 \\
\end{tabular}} & \multicolumn{2}{|c|}{ Phase 1} & \multicolumn{2}{|c|}{ Phase 2} & \multicolumn{2}{|c|}{ Phase 1} & \multicolumn{2}{|c|}{ Phase 2} & \multicolumn{2}{|c|}{ Phase 1} & \multicolumn{2}{|c|}{ Phase 2} \\
\hline & Error & Rate & Error & Rate & Error & Rate & Error & Rate & Error & Rate & Error & Rate & Error & Rate & Error & Rate \\
\hline \multirow{3}{*}{ ขอ } & $\partial$ & $21.84 \%$ & $\partial$ & $34.83 \%$ & $\partial$ & $30.77 \%$ & $\partial$ & $30.77 \%$ & $0:$ & $28.57 \%$ & $\partial$ & $50.00 \%$ & o: & $24.49 \%$ & $\partial$ & $21.28 \%$ \\
\hline & $0:$ & $16.09 \%$ & $\partial U$ & $7.87 \%$ & $\partial U$ & $7.69 \%$ & $\partial U$ & $15.38 \%$ & $\partial$ & $14.29 \%$ & & & $\partial$ & $16.33 \%$ & $\partial U$ & $8.51 \%$ \\
\hline & ઇəठ & $4.60 \%$ & o: & $2.25 \%$ & әขว & $7.69 \%$ & $\mathrm{u}:$ & $7.69 \%$ & & & & & әขә & $2.04 \%$ & o: & $6.38 \%$ \\
\hline
\end{tabular}

In Table 16, the FME rates of / $/ 2 /$ in Southwest and Jianghuai Sub-dialect Regions increase from $21.84 \%$ and $28.57 \%$ to $34.83 \%$ and $50.00 \%$ respectively; it in Northern Sub-dialect Region decreases from 24.49\% to 21.28\%; it in Northwest Sub-dialect Region remains at 30.77\%, which indicates the ineffective teaching. "The most common mistake of diphthongs is to be weakened into monophthongs" [21]. The diphthong /ひə/ are easily weakened into monophthongs / / / and / / :/ by students. Even though teachers have emphasized its correct pronouncing manner, students do not get it well, which indicates that students are under strong negative transfer impact of Chinese dialects.

\section{Conclusion}

L1 exerts transfer impact on English pronunciation unavoidably. The recording results show that Chinese students tend to confuse the similar Chinese phoneme and English phoneme, and they find it hard to pronounce the English phoneme which is absent in Chinese. Therefore, the negative transfer impact of Chinese dialects on English pronunciation is evident. The different articulating habits in different sub-dialect regions lead to the different pronouncing difficulties in learning English pronunciation. In teaching pronunciation, teachers should correct students according to the articulating habits in their dialect regions. Students should realize and overcome the negative transfer impact of Chinese dialects on English pronunciation, and enhance the positive transfer impact.

\section{Acknowledgement}

This paper is supported by Wuhan University of Technology Independent Innovation Research Fund and supervised by Professor Zhu Hanxiong. Project No. 2016-WY-A1-01.

\section{References}

[1] Dai, W. and Wang, D. (2002) Language Transfer Studies: Issues and Reflections. Journal of Foreign Languages, 6, 1-9.

[2] Wang, W. (1999) Review and Reflections of the Research on Language Transfer. Foreign Language Education, 1, 6-12.

[3] Yuan, B. (1995) Review and Perspective of Research in Second Language Acquisition. Chinese Teaching in the World, 4, 1995, 52-62.

[4] Chen, C., Ban, Y., Wang, Y. and Zhou, S. (2015) An Investigation of Transfer Impact of Chinese Dialects on English Pronunciation. 2015 2nd International Conference on Social Science. 
[5] Liu, N. (1988) A Comparison of the Main Features of Chinese and English Phonetic Systems. Journal of Nanjing Normal University (Social Science Edition), 3, 79-84.

[6] He, S. (1998) A Research on Changes in Sound Flow of English and Chinese. Foreign Languages and Their Teaching, 2, 14-18.

[7] Yu, L. (2004) Language Transfer and Second Language Acquisition-Review, Reflection and Research. Shanghai Foreign Language Education Press.

[8] Gui, C. (1985) Applied Phonology of American English. Shanghai Foreign Language Education Press.

[9] Wang, K. (2008) Chinese Students’ Difficulty in Learning English Pronunciation and Solutions. Journal of Southwest Guizhou Teachers’ College for Nationalities, 2, 24-29.

[10]Kenworthy, J. (1987) Teaching English Pronunciation. Longman.

[11]Sun, F. (2009) Contrastive Research on English and Chinese Consonants and Inspirations. Wenjiao Ziliao, 8, 51-52.

[12]Gui, C. (1978) A Comparison of the Main Features of the Phonetic Systems of Chinese and English. Modern Foreign Languages, 1, 44-50.

[13]Lei, B. (2009) Comparing English Phonetic Sounds with Chinese Ones and Teaching English Pronunciation. Journal of Kunming Metallurgy College, 4: 90-95.

[14]Dong, T. (2001) Chinese phonology. Zhong Hua Press.

[15]Zhang, S. (2009) On the Evolution of the Zhixi Initials in Northeastern Dialects. Chinese Linguistics, 1, 15-20.

[16]Wei, Z. (2003) An Introduction to Comparative Studies of English and Chinese. Shanghai Foreign Language Education Press.

[17]Liu, X. (2011) Studies on Zero Initial Syllables of Linyi Dialect. Shandong Normal University.

[18]Skandera P. and Burleigh P. A. (2005) Manual of English Phonetics and Phonology. Gunter Narr Verlag Tübingen.

[19]Che, L. (2013) Research on Negative Transfer Phenomenon of Qin Huangdao Dialect to the Acquisition of English Pronunciation. Inner Mongolia Normal University.

[20]Roach, P. (1991) English Phonetics and Phonology: A Practical Course. Cambridge University Press.

[21]Hao, J. and Hui, X. (2014) On Transfer of Vowel Sounds by English Learners in Cantonese-Speaking Area. Journal of Guangdong Polytechnic Normal University, 2, 52-58.

\section{Appendix}

\begin{tabular}{llllll}
\multicolumn{5}{c}{ Research } & \multicolumn{4}{c}{ Material } \\
touch & tree & passage & yard & zero & ship \\
joke & meeting & practice & pleasure & good & shower \\
gesture & people & careless & slip & cool & here \\
walk & trust & kindness & thing & over & ago \\
third & why & this & these & vote & fair \\
all & how & measure & dream & hot & poor \\
disaster & out & check & aid & option & casual \\
yet & high & run & boy & took & breathe \\
fool & English & thank & blame & blood & wealth \\
oil & text & principal & after & new & doctor
\end{tabular}

